\section{"Out of the map": mapping services and the access by individuals with disabilities living in social volnerability condition, in Santos City/SP, Brazil}

\title{
"Fora do mapa": mapeamento dos servicos e do acesso de pessoas com deficiência em situação de vulnerabilidade social no município de Santos/SP, Brasil
}

ABSTRACT: Introduction:

The text addresses the rights of mobility and assistance of people with disabilities, in Santos city, SP.

Objectives: The main aim of the present research is to address the supply and demand of services focusing on individuals with disabilities in order to widen, reflections about association among disability, social vulnerability and territory. Methods: Data were generated at three stages: the first stage comprised documentary survey about health services and social assistance provided to individuals with disabilities in Santos City-SP; the second stage referred to, six interviews conducted with individuals with disabilities, who lived in different regions in the city; and the third stage comprised services and the interviewees' location on the city map. Results:

Results were distributed on the map to enable the spatial visualization of services focusing on individuals with disabilities, as well as to check their concentration in Downtown and Urban Fringe regions. The comparison between the service and social vulnerability maps of the

City enabled identiffing the distance and low supply of services in zones of greater social vulnerability. The analysis applied to the interviews has pointed towards conflicts, difficulties and withdrawals from service usings, mainly among interviewees who lived in zones of greater social vulnerability. Conclusion: Cross-analysis of data provided by different sources enabled identifying a vulnerability expansion process. State plays the main role in this process, since social assistance, bealth and city-use rights are denied to these individuals on a daily

basis; access and territorialization policies are often ignored. The study also addressed the need of expanding the supply of territorial services to individuals with disabilities, as well as of assuring their access to, and use of, other regions in the city.

Keywords | Individuals with disabilities; Residence features; Social vulnerability; Community-Institution Relationships.
RESUMO: Introdução: $\mathrm{O}$ texto aborda os direitos de mobilidade e assistência das pessoas com deficiência, no município de Santos/SP. Objetivos: O objetivo central da pesquisa foi discutir as demandas e as ofertas de serviços voltados à pessoa com deficiência, favorecendo a reflexão mais ampla sobre a relação entre deficiência, vulnerabilidade social e território. Métodos: Os dados foram gerados a partir de três etapas: a primeira se caracterizou por levantamento documental de serviços de saúde e assistência social para pessoas com deficiência no município de Santos-SP; a segunda, por seis entrevistas com pessoas com deficiência, moradoras das diferentes regiões do município; a terceira, pela localização dos serviços e dos entrevistados no mapa da cidade. Resultados: A distribuição dos resultados no mapa permitiu a visualização espacial de serviços para pessoa com deficiência e constatar sua concentração nas regiões Centro e Orla. A comparação do mapa de serviços com o mapa da vulnerabilidade social do município permite identificar as distâncias e a baixa oferta nas áreas de maior vulnerabilidade social. Em seguida, a análise das entrevistas apontou para conflitos, dificuldades e desistências de uso de serviços, com especial destaque para os entrevistados que vivem nas áreas de maior vulnerabilidade social. Conclusão: A análise cruzada dos dados fornecidos pelas diferentes fontes permite identificar um processo de ampliação da vulnerabilidade tendo o Estado como protagonista, uma vez que direitos de assistência social, saúde e de uso da cidade são cotidianamente negados, e políticas de acesso e territorialização são ignoradas. Discute-se a necessidade de ampliar tanto a oferta de serviços territorializados para pessoas com deficiência, quanto a sua garantia de acesso e uso das outras regiões da cidade.

Palavras-chave | Pessoa com deficiência; Distribuição Territorial da População; Vulnerabilidade Social; Relações Comunidade-Instituição.

\footnotetext{
${ }^{1}$ Universidade Federal de São Paulo. Campus Baixada Santista. Santos, SP, Brasil
}

${ }^{2}$ Universidade Federal do Rio de Janeiro. Rio de Janeiro/RJ, Brasi. 


\section{INTRODUÇÃO|}

O presente trabalho apresenta os resultados obtidos na pesquisa intitulada "Direitos e acessibilidade das pessoas com deficiência, no município de Santos", realizada em Santos, São Paulo. O estudo buscou discutir as demandas, as ofertas e o uso de serviços voltados à pessoa com deficiência, analisando as relações entre deficiência, vulnerabilidade social e território. O recorte compreendeu serviços de saúde e de assistência social voltados especificamente ao público com deficiência.

A qualidade de vida e as oportunidades das pessoas com deficiência refletem as condições gerais da vida humana ao longo da história, somadas às políticas, aos contextos socioeconômicos em que se encontram e às representações e construções sociais acerca da deficiência.

Ao se olhar para o uso da cidade por pessoas com deficiência, no Brasil, contata-se que muitos de seus direitos são continuamente violados. Tais violações se agravam quando se trata de pessoas com deficiência que vivem em situação de vulnerabilidade social, a qual pode ser descrita como a conjunção das precárias condições socioeconômicas com a impossibilidade de exercer cidadania e suas potencialidades, somadas à fragilidade do vínculo social no âmbito mais nuclear ${ }^{1}$. No caso das pessoas com deficiência em vulnerabilidade social, soma-se falta de acesso e de informação às limitações que apresenta o território onde vivem.

Na cidade de Santos, a questão da pessoa com deficiência e seu acesso aos serviços aos quais tem direito se caracteriza de forma polarizada, dividida entre serviços ofertados pelo setor privado, com um perfil desenvolvimentista e aspecto luxuoso, por um lado, e uma rede pública bastante precária. A rede pública de serviços de saúde e assistência social voltados à pessoa com deficiência está altamente comprometida com a rede do terceiro setor, em sua maioria com perfil filantrópico - uma marca da cidade -, desenhando ampla variedade de assistência, porém limitada pela parceria público-filantrópico e concentrada em determinados locais da cidade.

Nesse contexto, e considerando especificamente a questão da pessoa com deficiência, o mapeamento das demandas e das ofertas de serviço é um importante instrumento para a identificação de demandas reprimidas e atendidas, relativas a essa população.
A pesquisa ora proposta tem relevância social na medida em que, ao identificarmos demandas de pessoas com deficiência em situação de vulnerabilidade social e mapearmos os serviços aos quais elas têm direito, podemos estudar e agir para que ocorram mudanças nas condições de acessibilidade geográfica, cultural e arquitetônica aos serviços e equipamentos sociais através de políticas públicas mais efetivas, bem como discutir com gestores, profissionais, conselheiros e familiares, a necessidade de tecnologias de atenção em saúde e assistência social a partir das demandas identificadas. Teve como objetivo central discutir sobre as demandas e as ofertas de serviços voltados à pessoa com deficiência, favorecendo a reflexão mais ampla sobre a relação entre deficiência, vulnerabilidade social e território.

Para tanto, foi traçado como objetivo operacional: localizar no mapa da cidade de Santos os serviços de saúde e de assistência social de atenção a pessoas com deficiência; discutir a relação entre o mapeamento dos serviços e o mapa da vulnerabilidade social do município; analisar a distribuição de pessoas com deficiência em situação de vulnerabilidade social, de acordo com o cadastro da Secretaria de Assistência Social do Benefício de Prestação Continuada para Pessoa com Deficiência - BPC/PcD; localizar em cada uma das cinco regiões do município uma pessoa com deficiência que aceitasse ser entrevistada; discutir sobre o acesso das pessoas com deficiência aos serviços aos quais têm direito, à luz das entrevistas; e discutir sobre a relação entre demanda e oferta levantadas.

O BPC/PcD é o Benefício garantido pela Política Nacional de Assistência Social à pessoa com deficiência em situação considerada de vulnerabilidade social. É direito garantido pela Constituição Federal $^{2}$ e regulamentado pela Lei Orgânica da Assistência Social (LOAS) ${ }^{3}$.

No Brasil, pessoa com deficiência é quem possui "impedimentos de longo prazo (pelo menos 2 anos) de natureza física, mental, intelectual ou sensorial. Os impedimentos podem obstruir sua participação plena e efetiva na sociedade em igualdade de condições com as demais pessoas"'.

De acordo com o Censo 2010 do Instituto Brasileiro de Geografia e Estatística - IBGE, no Brasil, existem 45,6 milhões de pessoas com algum tipo de deficiência, o que representa $23,92 \%$ da população brasileira ${ }^{5}$. 
As pessoas com deficiência física, em sua maioria, têm dificuldade para se locomoverem, e algumas utilizam dispositivos para auxílio, como andador, muletas e cadeira de rodas, necessitando de estrutura física adequada e recursos adaptados. A deficiência intelectual compromete o indivíduo em aspectos como comunicação e aprendizado ${ }^{8}$.

A legislação assegura o direito de acesso, circulação e utilização dos espaços públicos pelas pessoas com deficiência e pelas pessoas com mobilidade reduzida. Dá prioridade ao atendimento das primeiras em serviços públicos e privados e estabelece normas gerais e critérios básicos para a promoção da acessibilidade de ambas. Prima pelas condições de acessibilidade arquitetônicas, urbanísticas, de transportes, de comunicação e informação ${ }^{6}$. As leis descrevem os detalhes, desde o tamanho exato de uma rampa para acesso de deficientes físicos até faróis com som para deficientes visuais.

Segundo a Norma Brasileira NBR 9050/2004 Acessibilidade a edificações, mobiliário, espaços e equipamentos urbanos, emitida pela ABNT - Associação Brasileira de Normas Técnicas (Leis $\mathrm{n}^{\circ}$ 10.048/2000 e $n^{\circ} 10.098 / 2000$, Art. $8^{\circ}$ ), para fins de aplicação desta lei, considera-se 'acessibilidade':

Possibilidade e condição de alcance para utilização, com segurança e autonomia, dos espaços, mobiliários e equipamentos urbanos, das edificações, dos transportes, da informação e comunicação, inclusive seus sistemas e tecnologias, bem como outros serviços e instalações abertas ao público, de uso público ou privadas de uso coletivo, tanto na zona urbana como na rural, por pessoa com deficiência ou com mobilidade reduzida ${ }^{6}$.

$\mathrm{O}$ acesso e a acessibilidade aos serviços têm significados que se cruzam, mas diferem entre si. O termo 'acesso' significa a entrada do usuário no sistema e sua utilização; já "acessibilidade" se refere às características do serviço que contribuem de forma positiva ou negativa para a utilização dos usuários ${ }^{7}$. Nesse sentido, “a acessibilidade está relacionada à concepção de saúde como direito, intrínseca à condição de cidadania e constitui ação prioritária para a efetivação do SUS como pacto social"».

A acessibilidade tem duas dimensões principais: a sócioorganizacional, que corresponde à relação do serviço com o usuário, facilitando ou dificultando o acesso, e a dimensão geográfica, que envolve a distância do serviço da residência do usuário, custos relacionados e barreiras físicas ${ }^{7}$. A garantia de acessibilidade passa a ser uma melhoria de vida, trazendo mais conforto e segurança para as pessoas com deficiência, na medida em que podem ter livre acesso no território onde vivem.

Entretanto, mesmo com as leis e com os órgãos de vigilância que cobram dos locais públicos e privados a acessibilidade, muitos ainda não possuem adaptações, impossibilitando que as pessoas com deficiência tenham acesso garantido. As dificuldades aparecem tanto nos serviços quanto em todo o trajeto até o local, além de incluírem a falta de informação adequada, de gratuidades conquistadas e de atendimentos prioritários ${ }^{6}$.

A acessibilidade está relacionada diretamente ao território em que o indivíduo reside e às possibilidades de por ele se deslocar livremente, podendo estar comprometida não apenas pelas barreiras físicas, mas também pelas condições econômicas e fragilidades de redes sociais ${ }^{1}$.

Território é um espaço demográfico, epidemiológico, tecnológico, econômico, social e político, no qual diferentes sujeitos se articulam em torno de suas necessidades e interesses; é um espaço técnico-científico de produção de cultura e de valores ${ }^{10}$. O território, então, pode se tornar o principal facilitador ou obstáculo ao acesso aos serviços:

O território é espaço de possibilidades, de expressões concretas de como é possível permanecer vivo, apesar das dificuldades, sendo possível nele conhecer e atuar sobre o sentido atribuído às coisas, à vida, compreender e empreender a produção de valores e trocas sociais, um dos principais lugares de produção de saberes sobre o mundo, sobre a deficiência, sobre os problemas e de criação de soluções ${ }^{10}$.

O território é, portanto, o local de reconhecimento do sujeito. Pode-se, a partir dessa afirmativa, inferir que a oferta de serviços de reabilitação centralizados e distanciados de sua moradia, além de interpor obstáculos como barreiras físicas e de transporte, pela acessibilidade inadequada, despotencializa o território de vida do sujeito. Ao ser levado a percorrer grandes distâncias, o sujeito já não se identifica nos novos territórios e não reconhece seu território como potência de transformação para sua saúde. Nessa perspectiva, entendese que a vulnerabilidade é também constituída a partir das características do território e das políticas que o organizam? ${ }^{7}$.

Santos é a cidade-polo da região metropolitana Baixada Santista (São Vicente, Guarujá, Santos, Mongaguá, Ita- 
nhaém, Cubatão, Bertioga, Praia Grande e Peruíbe). Segundo o Censo 2013, o município possui 417.983 habitantes $^{11}$. Entre as cidades que compõem a Baixada Santista, Santos é a principal e de maior poder econômico, sendo o foco de procura de emprego pelos moradores das cidades vizinhas. A cidade tem grande importância no Brasil por possuir o maior Porto da América Latina, onde são recebidas e exportadas mercadorias para diversos países, sendo importante na economia da cidade e do país.

O Programa das Nações Unidas para o Desenvolvimento de 2010 posicionou a cidade de Santos em sexto lugar na lista dos municípios brasileiros e em terceiro lugar entre os municípios de São Paulo por índice de desenvolvimento humano?. Entretanto, a cidade apresenta alto custo de vida, especulação imobiliária e altas taxas de homicídios, e possui a maior favela de palafitas do país, com mais de 10 mil pessoas ${ }^{12}$.

Os habitantes do município ocupam 749 quilômetros quadrados de área ${ }^{11}$. A cidade de Santos situa se na ilha de São Vicente, mas o município conta também com a parte continental - a maior em extensão -, embora menor em habitantes, já que grande parte de sua área se caracteriza como Unidade de Conservação Ambiental. Os bairros que constituem a cidade possuem características muito diversificadas uns dos outros, pelos aspectos geográficos e também pelas questões socioeconômicas.

Cada zona exige atenção especial para que os serviços de saúde, educação, lazer, assistência social e outros sejam acessíveis a toda a população, assegurando seus direitos com qualidade. Entretanto, cabe perguntar como a acessibilidade vem se produzindo, enquanto direito, nas regiões da cidade.

A população em vulnerabilidade social se distribui pelas diversas zonas e tem ainda baixo acesso aos seus direitos. Por outro lado, vinda de um histórico de constituição da cidade fortemente apoiado na presença de igrejas e na lógica da caridade cristã, Santos possui grande número de Organizações Não Governamentais (ONGs), em sua maioria com perfil assistencialista, suprindo as questões que o Estado não consegue garantir. Atualmente, apesar do perfil ainda assistencialista, já não se mantêm prioritariamente pela via filantrópica, pois recebem subsídios governamentais.

Não foram encontrados dados precisos sobre a quantidade de pessoas com deficiência no município. Entretanto, desde o reordenamento dos serviços socioassistenciais orientado pelo Ministério de Desenvolvimento Social e Combate à Fome, a Secretaria Municipal de Assistência Social passou a fazer a gestão dos moradores que recebem o Benefício Assistencial de Prestação Continuada - BPC - para a pessoa com deficiência, antes controlado pela previdência social. Esse benefício destina-se às pessoas com deficiência que não tenham condição de se manter, ou seja, o cadastro do BPC no município nos apresenta o quantitativo de moradores da cidade que têm deficiência e estão em vulnerabilidade social. De acordo com esse cadastro, o município, em 2013, pagava o BPC para 1520 pessoas com deficiência. É preciso, entretanto, alertar para o fato de que a concentração desse benefício para a gestão da Assistência Social era recente no município, de forma que o trabalho de busca ativa e novos cadastramentos ainda não estava vigorando de forma ordenada, sendo tal número referente principalmente àqueles beneficiários que estavam cadastrados anteriormente.

\section{MÉTODOS|}

O estudo apresenta resultados de pesquisa realizada na cidade de Santos nos anos de 2012 a 2015. Caracteriza-se por pesquisa quali-quantitativa, envolvendo estudo documental a partir de consultas a bases de dados públicos e entrevistas semiabertas com pessoas com deficiência. Os entrevistados foram contatados a partir do Conselho da Pessoa com Deficiência do município, tendo como critérios de inclusão serem maiores de idade, terem condição de compreender e responder às questões da entrevista, aceitarem participar do estudo e serem ao todo um morador de cada uma das diferentes regiões da cidade. As questões da entrevista versavam sobre o uso da cidade e dos serviços voltados à pessoa com deficiência.

A primeira etapa da pesquisa foi caracterizada pelo levantamento (a) do cadastro de pessoas com deficiência em vulnerabilidade social e (b) dos serviços voltados a essa população, seguido de sua localização de acordo com as regiões da cidade.

Para o mapeamento das pessoas com deficiência em vulnerabilidade social moradoras do município, realizouse mapeamento das pessoas cadastradas no BPC - PcD municipal, com base em levantamento de beneficiários no 
cadastro da Secretaria de Assistência Social (SEAS) e sua respectiva localização de acordo com as regiões da cidade.

Para o mapeamento dos serviços de saúde e assistência social voltados à pessoa com deficiência, buscou-se o cadastro dos serviços no Conselho Municipal da Pessoa com Deficiência (CONDEFI), procedendo à respectiva localização no mapa da cidade.

A segunda etapa constou de entrevistas com cinco pessoas com deficiência, cada uma moradora de uma região do município de Santos, assim distribuídas: Zona Noroeste, Região Central-Portuária, Zona Orla e Intermediária, Zona Continental e Zona dos Morros. Para localizar possíveis entrevistados, foi contatado o CONDEFI que, além de sugerir alguns entrevistados, também sugeriu outras fontes de contato. A pesquisa de campo foi realizada durante o ano de 2013.

O estudo foi submetido ao Comitê de Ética via Plataforma Brasil/Ministério da Saúde (CAAE 24442513.9.0000.5505). Foi assinado o Termo de Consentimento Livre e Esclarecido (TCLE) por todos aqueles que concordaram em participar. Todas as entrevistadas estão identificadas por nome fictício, e não foram citados endereços dos participantes, protegendo assim suas identidades e garantindo o sigilo dos cadastros.

A análise dos dados se deu a partir de dois focos. Estudo documental: Para as informações levantadas baseadas no estudo documental, foi realizada técnica de localização dos dados de serviços no mapa da cidade e quantificação dos usuários do BPC-PcD por região.

Entrevistas: Para tratamento das entrevistas, foi utilizada a análise do conteúdo, a partir de agrupamento semântico de respostas referentes aos objetivos da pesquisa. Os nomes usados são fictícios.

Em seguida, dados do estudo documental e das entrevistas foram cruzados, visando ampliar as possibilidades de análise e discussão com base na comparação de informações sobre demandas (local de moradia e deslocamentos) e sobre ofertas (localização dos serviços específicos).

\section{RESULTADOS/DISCUSSÃO|}

Os documentos levantados - lista de serviços e cadastro do $\mathrm{BPC} / \mathrm{PcD}$ - foram tratados inicialmente a partir da localização dos endereços no mapa da cidade.

Optou-se, aqui, por apresentar os mapas e suas análises em sequência: distribuição dos serviços, distribuição das Zonas (Figura 1), mapa da vulnerabilidade social e concentração dos BPC/PcD da cidade. Logo após, apresenta-se a análise dos dados das entrevistas.

Figura 1 - Mapa das regiões da cidade de Santos

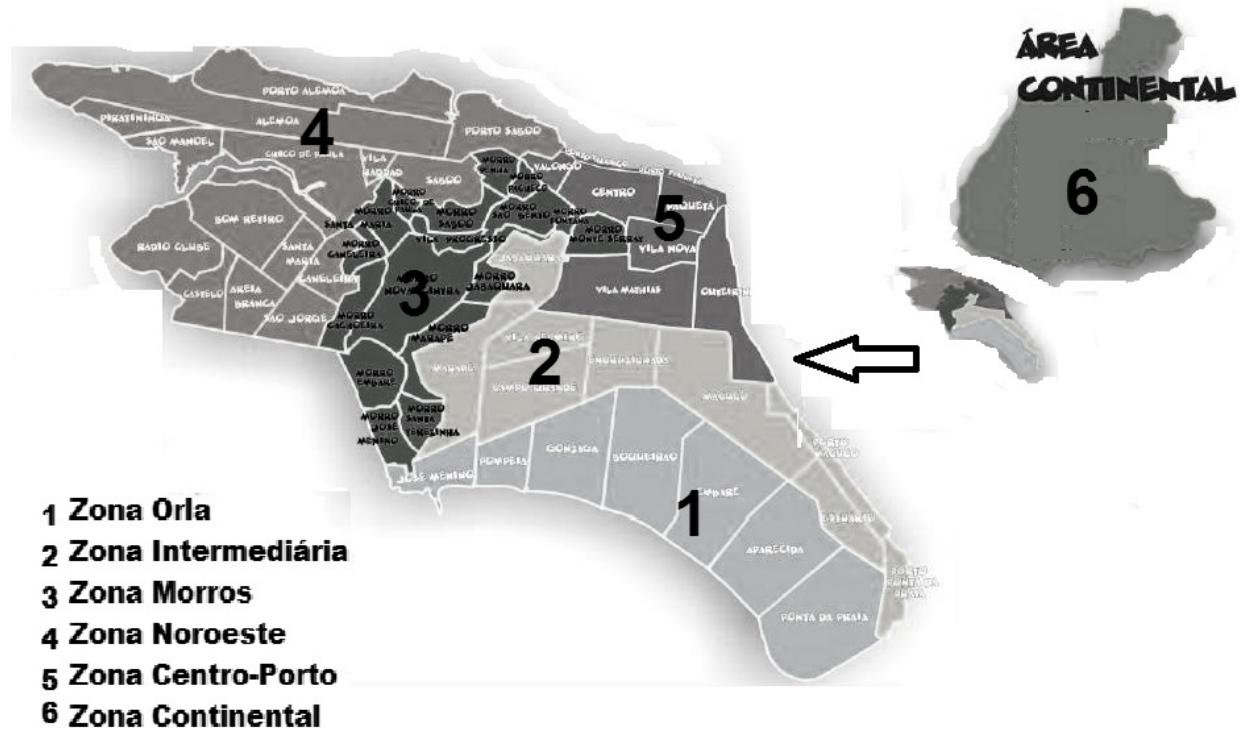

Fonte: Dicas de Santos ${ }^{13}$. 
O mapeamento dos serviços para as pessoas com deficiência em Santos é um importante objeto de estudo para analisarmos a concentração dos serviços em determinadas regiões e relacionar sua distribuição às demandas dessa população, podendo-se discutir sobre o território, sobre o acesso aos serviços e sobre a vulnerabilidade social.

O mapa da cidade se divide em seis zonas, como demonstra a Figura 1: Orla Marítima, Zona Intermediária, Zona Central-Portuária, Zona Morros, Zona Noroeste, e Zona Continental. O mapa utilizado como base para os dados levantados é o mapa oficial de distribuição das regiões da cidade.

Depois do contato com o CONDEFI, foi acessada a lista com nomes e endereços das instituições que atendem à pessoa com deficiência no município, tanto da saúde quanto da assistência social. Tal lista, ao ser localizada no mapa da cidade, permite visualizar a distribuição de tais serviços no município estudado, conforme Figura 2.

Figura 2 - Mapa dos serviços especializados no atendimento a pessoas com deficiência em Santos
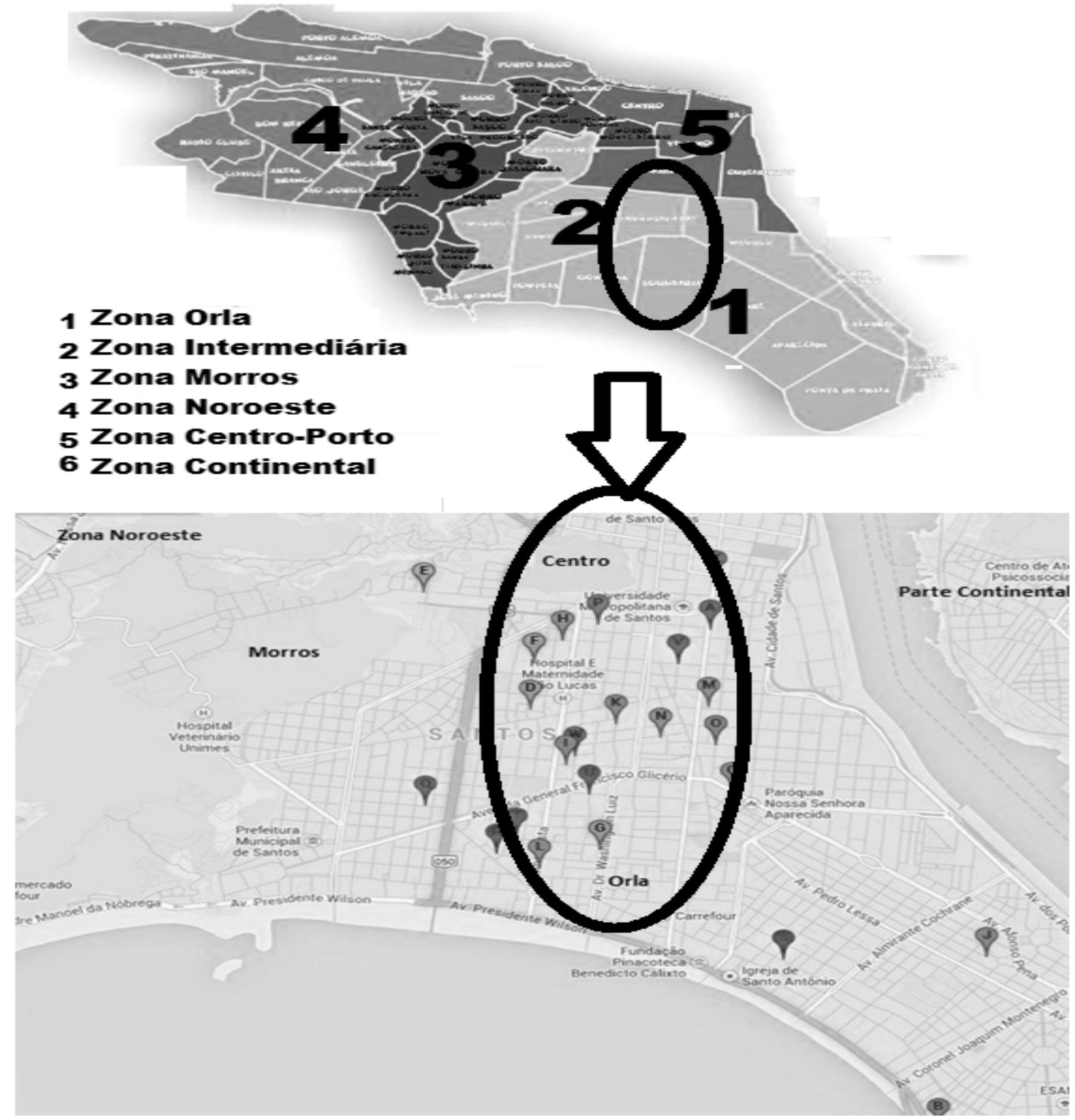

Fonte: Dicas de Santos ${ }^{13}$ e Google Maps ${ }^{14}$. 
Como pode ser observado no mapa a seguir, há uma grande concentração de serviços voltados à pessoa com deficiência nas regiões do Centro e da Zona Orla-Intermediária da cidade, que são também as regiões as quais concentram a população com maior poder aquisitivo e em menor vulnerabilidade social.

A administração pública do município reúne as Zonas Orla e Intermediária como uma única regional, visando ao ordenamento e distribuição dos serviços. Sendo assim, são consideradas cinco regiões, e não seis, para as redes de serviços.

Acima, identifica-se a zona urbana do município, com destaque para a concentração de serviços nas zonas OrlaIntermediária e parte do Centro.

De acordo com a Secretaria Municipal de Assistência Social de Santos, a maior concentração da população em vulnerabilidade social ocorre nas regiões Morros, Noroeste, Continental e Centro-Porto. Considerando a Figura I, essas Zonas corresponderiam às Zonas 3, 4, 5 e 6.

Ou seja, a Zona Orla-Intermediária, embora receba de forma concentrada boa parte dos serviços voltados à pessoa com deficiência, não corresponde às regiões de maior vulnerabilidade social da cidade. Isso, em oposição, significaria afirmar que as regiões de maior vulnerabilidade social da cidade são também as que têm menor número de serviços voltados a essa população.

O Brasil, durante o século XX, viveu um projeto de urbanização baseado na lógica europeia de concentração de serviços especializados nas regiões centrais ${ }^{16}$. Sobre o debate em torno da alocação de serviços, identifica-se a forte problemática existente na contraposição entre a "relação acessibilidade/concentração de serviços, por um lado, e o padrão territorial da oferta de cuidados, por outro" $"$.

Essa concentração geográfica de serviços vem sendo arduamente enfrentada pelas Políticas Nacionais de Saúde, Educação e Assistência Social por meio dos processos de territorialização, mas encontra sérias barreiras, tanto físicas quanto culturais, além das disputas de interesses econômicos e políticos.

A Secretaria Municipal de Assistência Social de Santos contava, à época da pesquisa, com sete Centros de
Referência em Assistência Social (CRAS) e uma subsede, distribuídos de acordo com as Zonas já citadas. O cadastro do Benefício de Prestação Continuada para pessoa com deficiência (BPC/PcD) do município de Santos, em 2013, contabilizava 1520 usuários, assim distribuídos de acordo com os CRAS e as Zonas (Tabela 1).

Tabela 1 - Distribuição de CRAS e de BPC/PcD por região

\begin{tabular}{lcc}
\hline Região & CRAS & N $^{\circ}$ BPC/PcD \\
\hline Zona Centro-Porto & 1 & 437 \\
Zona Continental & 1Subsede & 15 \\
Zonas Orla e Intermediária & 1 & 442 \\
Zona Noroeste & 3 & 398 \\
Zona Morros & 2 & 228 \\
\hline
\end{tabular}

Fonte: Secretaria Municipal de Assistência Social de Santos ${ }^{15}$.

De acordo com essa distribuição, identificamos grande concentração de BPC da Pessoa com Deficiência nas duas regiões mais assistidas pelos serviços destinados a essa população: o Centro e a Zona Orla-Intermediária. Tal concentração contribui para o levantamento de algumas hipóteses: é possível que a concentração de serviços esteja atraindo moradores com deficiência para essas áreas; pode-se questionar também se a lógica que distribui maior número de BPC/PcD nessas Zonas seria a mesma da concentração de serviços, qual seja: a perversa lógica que assiste mais e melhor aos que já são assistidos; ou ainda, é possível considerar que de fato haja uma maior concentração de pessoas com deficiência nessas regiões, justificando a concentração de serviços e de BPC/PcD.

Entendemos que a questão da garantia do direito da pessoa com deficiência não se determina pela oferta de serviços no território de residência apenas, podendo ser composta por combinações entre oferta, demanda e meios de acesso ${ }^{17}$. Sendo assim, torna-se relevante compreender como as pessoas com deficiência residentes em diferentes regiões acessam e utilizam os serviços concentrados em certas regiões da cidade.

As entrevistas foram realizadas nas cinco regiões da cidade de Santos: Zonas Noroeste, Continental, Orla-Intermediária, Morro e Centro-Porto. O público entrevistado foi de pessoas com deficiência, contatadas por indicações do CONDEFI. Por esses contatos, foram indicados dez possíveis participantes, dos quais foi possível contatar cinco, sendo um de cada Zona, de acordo com a divisão 
de regiões da cidade. A entrevista teve como objetivo investigar a relação entre demanda, acessibilidade e serviços utilizados, buscando discutir o uso da cidade e dos serviços por pessoas com deficiência na cidade de Santos. Ainda que pesquisas recentes apontem para a importância de se considerar a dimensão territorial nos processos de tomada de decisão na oferta dos serviços, as entrevistas demonstram certo descompasso no que diz respeito à relação entre demandas, territórios e ofertas de serviços ${ }^{17}$.

Todos os entrevistados eram do sexo feminino e tinham entre 40 e 60 anos de idade. Embora não fosse um recorte proposto pela pesquisa, todas as entrevistadas possuem deficiência física, o que leva à suspeita de que o tema "pessoa com deficiência e acessibilidade aos serviços" tenha induzido à compreensão da acessibilidade física, promovendo assim o recorte das pessoas que foram indicadas pelos serviços.

Das cinco entrevistadas, duas possuem a deficiência desde a infância: Olga (Moradora do Centro) e Maria (Moradora da Orla-Intermediária); essas duas frequentaram a escola. Olga se locomovia por meio da van da escola, e Maria, por meio de bicicleta. Olga e Maria relatam não precisar mais de serviços de reabilitação física, pois não teriam mais melhorias. Segundo elas, a evolução possível na reabilitação se deu durante a infância, quando frequentavam serviços de reabilitação física. Atualmente utilizam apenas UBS e plano de saúde particular quando necessitam de serviços da saúde. Dessa forma, Olga (residente do Centro) e Maria (residente na Orla) utilizaram serviços localizados no Centro enquanto necessitaram e informam facilidade de acesso devido à ampla rede de transporte público nas regiões onde residem.

Patrícia (Moradora do Morro) adquiriu a deficiência a partir dos 55 anos. Fazia fisioterapia e tinha dificuldade para se locomover até o local, pois, segundo ela, o transporte público não era preparado para atendê-la, relatando ter sofrido acidente no ônibus. Além disso, diz ter parado de frequentar o serviço de reabilitação física por não ter mais receita médica para realizá-la. Atualmente, frequenta a Unidade Básica de Saúde (UBS) da região em que reside e participa de um projeto em Organização Não Governamental. Para a UBS, vai a pé e, para a ONG, há um transporte da própria organização que a busca em sua residência. Nota-se, no mapa, a distância de sua residência (Morro) até o serviço que lhe foi indicado (Centro), sendo o trajeto uma barreira de acessibilidade de grande relevância apontada pela entrevistada. A falta de adequação do transporte público e de seus funcionários também foi citada, devido a dificuldades, como subir ao ônibus, e falta de atenção dos motoristas.

Renata (moradora da região Noroeste) relata não ter acesso ao local para o qual foi encaminhada para fazer fisioterapia, tanto pela distância quanto por ter dificuldade de usar o ônibus, já que não conseguiu o transporte especializado da prefeitura para buscá-la. Não sai de casa com receio de cair, pois sua marcha é muito comprometida. Necessita de atendimento com fisioterapeuta, mas está aguardando indicação de um local mais próximo e com melhor acesso. Assim, necessita do serviço que está localizado no Centro, mas, devido à distância e à dificuldade na marcha (que não permite enfrentar as barreiras físicas e arquitetônicas da cidade), não utiliza o serviço, com receio de quedas.

Nara (Moradora da Zona Continental) nunca utilizou qualquer serviço de reabilitação física. Foi atropelada e ficou com dificuldade de andar, utilizando bengala para auxílio. Caiu na rua devido a barreiras físicas (um buraco), e machucou o joelho; foi internada e, ao sair do hospital, passou a utilizar cadeira de rodas. Não frequenta qualquer serviço de reabilitação física porque, embora necessite, a reabilitação nunca lhe foi recomendada pelo médico da unidade de saúde de seu bairro que, segundo ela, não a encaminha em virtude da distância a partir de sua residência. Entre todas as entrevistadas, apenas essa última - Nara - tem conhecimento do $\mathrm{BPC} / \mathrm{PcD}$, que recebe há poucos meses.

Assim, ao analisar a relação entre os locais onde residem as entrevistadas e os respectivos serviços que frequentaram ou deveriam frequentar, verifica-se que aquelas que tiveram acesso a atendimento especializado são exatamente as que residem nas áreas nas quais há concentração dos serviços (Figura II). Da mesma forma, é possível verificar que as entrevistadas que deixaram de ter atendimentos especializados, apesar dos encaminhamentos e da identificação da necessidade, são as que residem nas regiões Morro e Noroeste, onde não se encontram serviços especializados (Figura 2). O quadro mais grave, entretanto, se apresenta na região Continental, na qual a entrevistada relata não conseguir sequer o encaminhamento para atendimentos especializados, dada a distância e a impossibilidade do acesso. 
Ao se sobrepor o mapa da vulnerabilidade social com o mapa da oferta de serviços especializados, identificamos a repetição das violações dos direitos das pessoas com deficiência moradoras das regiões vulneráveis, uma vez que à deficiência e à pobreza se somam a ausência de oferta de serviços especializados em seu território, a distância dos serviços especializados, a dificuldade de transportes e a falta de estrutura urbana que lhes garanta o acesso aos serviços indicados.

Entre as que residem nas regiões de maior vulnerabilidade, os motivos de não frequentarem tais serviços são os mesmos: a dificuldade na acessibilidade, transporte mal estruturado, calçadas irregulares, insegurança ao sair de casa. Elas relatam preferir continuar com as limitações que já têm a adquirirem novas limitações, com as possíveis quedas no trajeto inseguro. Temem que sua vulnerabilidade aumente ainda mais, podendo chegar à necessidade de serem internadas em hospitais ou asilos.

Pesquisas que relacionam o acesso com a exclusão social mostram que esta não ocorre devido à falta de oportunidades, mas à falta de acesso a essas oportunidades ${ }^{18}$. O acesso da população aos serviços de reabilitação é um requisito para uma eficiente assistência, sendo a localização geográfica dos serviços um dos fatores que interferem nessa acessibilidade ${ }^{19}$.

Os direitos de acesso à reabilitação e de ir e vir, que deveriam ser garantidos a todo cidadão, não são assegurados às pessoas com deficiência - principalmente aquelas que vivem nas regiões de vulnerabilidade social do município, impedindo uma das entrevistadas (Renata), que reside sozinha, até de sair de sua casa para comprar alimentos e realizar atividades básicas no território onde reside. Essas limitações produzem sofrimento constante perceptível durante as entrevistas, marcadas por choros e denúncias. A não garantia dos direitos básicos, em última instância, é a afirmação do não lugar e de uma subcidadania na cidade.

A despeito do Decreto Federal no 3.298/99 - que estabeleceu extensa relação de obrigações para o setor público, garantindo a pessoas com deficiência o acesso a serviços de reabilitação, atendimento domiciliar de saúde e desenvolvimento de programas com a participação da comunidade - não se materializam em algumas áreas de vulnerabilidade, como essas nas quais reside a maior parte das entrevistadas, áreas marcadas pela presença da pobreza e pela ausência do Estado ${ }^{20}$.
Lembrando pesquisa realizada por Cunha ${ }^{21}$, a acessibilidade é considerada uma característica adicional à mera presença ou disponibilidade de um serviço. Em sua pesquisa, essa autora demonstra que, ainda que haja intenção política dos municípios em diminuírem as barreiras de acesso, a efetivação de tal objetivo não se constata.

Os mapas evidenciam e as entrevistas ilustram o cenário de exclusão promovido por essa perversa centralização dos serviços especializados para a pessoa com deficiência, levando à constatação de que muitos moradores da cidade vivem em condições marginais, dependendo da ajuda de vizinhos e não acessando direitos básicos. Com relação ao acesso ao $\mathrm{BPC} / \mathrm{PcD}$, que até pouco tempo foi responsabilidade da Previdência Social, verifica-se que, desde sua transição para a gestão da Assistência Social, em 2012, a maior parte do trabalho direcionou-se à localização dos então já beneficiários e sua vinculação aos CRAS de seus territórios, não havendo ainda uma campanha de divulgação e orientação às pessoas que ainda não o recebem.

Com relação aos maus tratos e despreparo de profissionais frente à deficiência, foram citados principalmente os motoristas de ônibus, que não respeitam as limitações de tempo e deslocamento dos sujeitos, tanto para entrar quanto para sair do ônibus, e os médicos, que não receitam as sessões de fisioterapia ou agem com indiferença ante o sofrimento.

Vale destacar que, ainda que todos os ônibus do município sejam adaptados com as normas da ABNT, a falta de cobradores nos ônibus e a necessidade de atender às diversas demandas dos usuários, somadas à falta de preparo dos motoristas, levam o transporte público à condição de inadequação. Além disso, os próprios profissionais de saúde parecem já não investir no sistema de apoio e reabilitação à pessoa com deficiência, deixando de indicar, incentivar e garantir às pessoas com deficiência o acesso a seus direitos, passando a simplesmente repetir o abandono do Estado ao deixar de encaminhá-las aos serviços a que têm direito.

Observa-se que a oferta de serviços de reabilitação física no município, quando não é acompanhada pela garantia de acesso, torna, de novo, vítimas as populações mais vulneráveis. O serviço não terá eficácia no tratamento se, para acessá-lo, for necessário enfrentar barreiras físicas e constrangimentos. A estrutura da cidade passa a ser um empecilho e não um facilitador para o acesso e uso. 


\section{CONCLUSÃO|}

Percebe-se, com este estudo, que o principal questionamento dos participantes é a falta de acessibilidade aos serviços de reabilitação. Entre as barreiras citadas, encontram-se a distância geográfica, a concentração de serviços em algumas regiões da cidade, o fato de os motoristas dos ônibus não estarem preparados, a falta de cuidado adequado para com as ruas e calçadas, a dificuldade de acesso ao transporte público especializado, a falta de encaminhamento aos serviços aos quais têm direito e a falta de orientação sobre tais direitos.

O território, ao mesmo tempo em que pode ser um facilitador/potencializador de acesso aos serviços para pessoas com deficiência, também pode se caracterizar como mais um fator de sua vulnerabilidade.

A constatação da falta de garantias de acesso às populações residentes nas regiões constantes no mapa de vulnerabilidade da cidade aponta para a necessidade de construção de programas de Reabilitação Baseada na Comunidade - iniciativa já reconhecida e acolhida pelo Ministério da Saúde -, criando laços com a comunidade e auxiliando no processo de apoio e acompanhamento à pessoa com deficiência, o que produzirá modos de realizar a reabilitação e tornará o território não um empecilho, mas sim um fator protetor e potencializador de relações e de saúde das pessoas com deficiência em situação de vulnerabilidade social.

$\mathrm{O} \mathrm{BPC} / \mathrm{PcD}$ não foi mencionado pelas pessoas entrevistadas, e a quase totalidade não tinha conhecimento de sua existência, ainda que tenha sido observada a necessidade dessa garantia, dada as condições de vida dos sujeitos entrevistados.

Ainda que a cidade seja a $17^{\mathrm{a}}$ cidade mais rica e o $5^{\circ}$ Índice de Desenvolvimento Humano do país, o planejamento para garantir os direitos da população não parece dar conta das vulnerabilidades existentes, e as desigualdades se reafirmam nos modos de uso da cidade pelas pessoas com deficiência. Os moradores que possuem melhor poder aquisitivo residem em regiões com ótimos índices de qualidade de vida, contando com estrutura pública e serviços privados de alta qualidade, enquanto aquelas em situação de vulnerabilidade social residem em regiões com características de abandono do Estado, tendo assim seus direitos duplamente violados, tanto pela ausência dos serviços públicos de qualidade quanto pela impossibilidade de acesso aos serviços privados.

Considerando os dados dos serviços de saúde e do cadastro da Assistência Social, verifica-se que o necessário diálogo intersetorial se faz ainda incipiente no que tange à população pesquisada.

O estudo apresenta dados exploratórios, tendo apenas uma entrevista por região e pouco aprofundamento no que diz respeito à análise da distribuição do $\mathrm{BPC}-\mathrm{PcD}$ por regiões, o que indica a necessidade de novos estudos nessa direção.

A pesquisa traz contribuições para o debate acerca das políticas de acesso, da garantia de direito e da intersetorialidade de serviços para a pessoa com deficiência. Ele também evidencia a reprodução da desigualdade socioespacial na distribuição de serviços e de $\mathrm{BPC} / \mathrm{PcD}$ na cidade de Santos.

\section{REFERÊNCIAS |}

1. Silva CR, Freitas HI. Adolescentes em situação de vulnerabilidade: estratégias de terapia ocupacional em um trabalho de prevenção a Aids. Cad Terap Ocup. 2003; 11(2)111-7.

2. Brasil. Constituição (1988). Constituição da República Federativa do Brasil. Brasília: Senado Federal; 1988.

3. Brasil. Lei $n^{\circ}$. 8.742, de 7 de dezembro de 1993. Dispõe sobre a organização da Assistência Social e dá outras providências. Diário Oficial da União 08 dez 1993.

4. Brasil. Lei $n^{\circ}$. 12.470, de 31 de agosto de 2011. Altera os arts. 21 e 24 da Lei $n^{\circ}$ 8.212, de 24 de julho de 1991, que dispõe sobre o Plano de Custeio da Previdência Social, para estabelecer alíquota diferenciada de contribuição para o microempreendedor individual e do segurado facultativo sem renda própria que se dedique exclusivamente ao trabalho doméstico no âmbito de sua residência, desde que pertencente a família de baixa renda [...]. Diário Oficial da União 01 set 2011.

5. Instituto Brasileiro de Geografia e Estatística (IBGE). Atlas do Desenvolvimento Humano no Brasil [nternet]. Ranking: todo o Brasil (2010) [acesso em 20 jan 2019]. 
Disponível em: URL: http://cidades.ibge.gov.br/painel/ painel.php?codmun $=354850$.

6. ASSOCIAÇÃO BRASILEIRA DE NORMAS E TÉCNICAS. ABNT NBR 9050: acessibilidade a edificações, mobiliário, espaços e equipamentos urbanos. Rio de Janeiro: ABNT; 2004.

7. Silvia NF. Análise da acessibilidade aos serviços de saúde na perspectiva dos usuários: um estudo de caso no Baixo Amazonas. Belém. Dissertação [Mestrado em Desenvolvimento e Meio Ambiente Urbano]. Universidade da Amazônia; 2012.

8. Silva Junior ES, Medina MG, Aquino R, Fonseca ACF, Vilasbôas AL. Acessibilidade geográfica à atenção primária à saúde em distrito sanitário do município de Salvador. Rev Bras Saúde Mater Infant. 2010; 10(Supl. 1)49-60.

9. Oliver FC, Almeida MC. Abordagens comunitárias e territoriais em reabilitação de pessoas com deficiências: fundamentos para terapia ocupacional. In: De Carlo MMRP, Bartalotti CC, organizadoras. Terapia ocupacional no Brasil: fundamentos e perspectivas. São Paulo: Plexus; 2001. p. 81-98.

10. Oliver FC, Ghirardi MIG, Almeida MC, Tissi MC, Aoki M. Reabilitação no território: construindo a participação na vida social. Rev Ter Ocup. 2001; 12(1/3)15-22.

11. Vasconcelos LR, Pagliuca LMF. Mapeamento da acessibilidade do portador de limitação física a Serviços Básicos de Saúde. Esc Anna Nery. 2006; 10(3)494-500.

12. Challoub HI. Editorial. Jornal Primeiro Texto [Internet]. Disponível em: URL: http://caminhosaosebastiao. blogspot.com.br/2013/12/do-caminho-sao-sebastiaopara-franca.html.

13. Dicas de Santos. Mapa da cidade de Santos por Região. Dicas de Santos [internet]. Disponível em: URL: http:// www.dicasdesantos.com.br/2009/03/mapa-da-cidade-desantos-por-zona.html.

14. Google Maps. Mapa de Santos. 2016. Disponível em: URL: https://www.google.com.br/maps/place/Santos.

15. Secretaria Municipal de Assistência Social de Santos (SEAS). Cadastro de beneficiários do programa Benefício de Prestação Continuada, modalidade Pessoa com Deficiência. 2013.

16. Costa S, Silva CRC. Afeto, memória, luta, participação e sentidos de comunidade. Pesqui Prát Psicossociais. 2015; 10(2):283-91.

17. Santinha G. Cuidados de saúde e território: um debate em torno de uma abordagem integrada. Saúde Soc. 2013; 22(3):815-29.

18. Brasil. Decreto nº. 3298, de 20 de dezembro de 1999. Regulamenta a Lei no 7.853, de 24 de outubro de 1989, dispõe sobre a Política Nacional para a Integração da Pessoa Portadora de Deficiência, consolida as normas de proteção, e dá outras providências. Diário Oficial da União 21 dez 1999.

19. Akerman M, Sá RF, Moyses S, Rezende R, Rocha D. Intersetorialidade? IntersetorialidadeS! Ciênc Saúde Coletiva. 2014; 19(11)4291-300.

20. Unglert CVS, Rosenburg CP, Junqueira CB. Acesso aos serviços de saúde: uma abordagem de geografia em saúde pública. Rev Saúde Pública.1987; 21(5)39-46.

21. Cunha ABO, Vieira-da-Silva LM. Acessibilidade aos serviços de saúde. Cad Saúde Pública. 2010; 26(4):725-37.

Correspondência para/Reprint request to:

Samira Lima da Costa

Av. Pasteur, 250, fundos,

Campus Praia Vermelha,

Botafogo, Rio de Janeiro/RJ, Brasil

CEP: 22290-902

E-mail: biasam2000@gmail.com

Recebido em: 28/09/2017

Aceito em: 28/08/2020 